\title{
Reflexões sobre a prática da memória no ofício do ator de teatro
}

\author{
François Kahn ${ }^{1}$ \\ Tradução de Luiza Jatobá
}

"Esta contradição entre espontaneidade e precisão é natural e orgânica. Uma vez que cada um destes aspectos é um polo da natureza humana, por essa razão, quando eles se entrecruzam nós ficamos inteiros. Em um certo sentido, a precisão é o campo de ação da consciência, a espontaneidade - por outro lado - do instinto. Em outro sentido - ao contrário - a precisão é o sexo, enquanto a espontaneidade é o coração. Se o sexo e o coração são duas qualidades separadas, então estamos cindidos. Só quando existem juntos, não enquanto união de duas coisas, mas como uma coisa única, estamos inteiros. Nos instantes de plenitude, o que em nós é animal não é unicamente animal, mas toda a natureza. Não a natureza humana, mas toda a $\mathrm{Na-}$ tureza no homem" (Jerzy Grotowski)

memória é uma ferramenta fundamental no ofício do ator. Isso é tão óbvio que seu estudo é esquecido: parece tão simples, quase mecânico ou talvez eletrônico, como se o nosso cérebro fosse um tipo de computador onde bastasse dar um upgrade e au- mentar sua capacidade de memória. Mas não é assim que funciona. A memória é orgânica, inscrita em nosso corpo. Tem uma duração mais ou menos longa.Tem "centros" diferentes, segundo o tipo de informação memorizada. Ela tem um antagonista de peso, outra ferramenta fundamental, o esquecimento, que apaga os dados ou os coloca em uma gaveta secreta: o inconsciente. Por fim, ela é essencialmente diferente para cada individuo, quanto ao conteúdo e quanto ao funcionamento.

Não vou tratar aqui de questões teóricofilosóficas da memória, nem de questões neurofisiológicas. O que me interessa é a prática, o trabalho propriamente dito da memória no ofício do ator. Se eu especifico o ator de teatro, é que se trata do campo limitado de minha experiência e tudo que se segue corresponde a essa experiência pessoal como ator, diretor e pedagogo. Para expor esta prática, vou me ater a duas aplicaçôes bem particulares: por um lado, o trabalho de memorização de um texto, e por outro, o trabalho de improvisação estruturada. Concluirei com uma reflexão sobre a relação entre memória e organicidade.

François Kahn é ator e encenador.

1 Citação do texto "Resposta a Stanislavski”. É um texto que foi primeiramente redigido por Leszek Kolankiewicz a partir da transcrição do encontro de Grotowski com encenadores e atores da Brooklyn 


\section{Prática da memória voluntária: a memorização de um texto}

Se perguntamos aos alunos das escolas de arte dramática como eles memorizam seus textos, as respostas não variam muito e quase sempre referem-se a métodos utilizados por eles no colégio ou no colegial, mas que vem mesmo da escola primária. Estes métodos se baseiam, em geral, numa infindável repetição do texto em voz mais ou menos alta, uma cantilena acompanhada de movimentos repetitivos, associados a uma perda quase total do sentido do que está sendo enunciado; e para compensar o tédio que provoca esta ladainha, se produz um tipo de ênfase emocional, o mais das vezes totalmente convencional. Este procedimento provoca no jovem ator um tipo de ambivalência neurótica combinando o desgosto destas longas horas monótonas (quando ainda aprendemos nossas lições não por interesse pessoal mas por obrigação ou mesmo para agradar aos nossos pais e professores), com um tipo de auto-satisfação narcísica por escutar a própria voz. Logo em seguida, o trabalho com professores de dicção introduz numerosas correçôes (análise do texto em seu sentido literal, sua musicalidade, seu sentido escondido, etc...) que vão reavivar o interesse do aluno, mas geralmente não chegam a descartar os velhos padrôes da memorização que, justamente porque foram consolidados pelo hábito, parecem mais seguros e confortáveis.

Quando formulamos a mesma pergunta a atores profissionais (e aqui me refiro a atores de alto nível profissional) ficamos surpresos ao descobrir que, para muitos, a memorização permanece um problema mal resolvido que provoca cansaço, angústia e até sofrimento. ${ }^{2}$ Quase sempre isto intensifica o medo dos atores: seu pavor do "branco", de perder o fio da meada. Por causa disso, os atores invariavelmente, no começo dos ensaios, se agarram ao texto como se fosse uma tábua de salvação. Isto não só cerceia consideravelmente a liberdade de reação e de criação do ator durante os ensaios, mas também adia o momento do ator se separar de seu texto. Portanto, uma memorização mal feita apenas provoca no ator um excesso de tensão interior totalmente inútil, e não resolve nem um pouco o verdadeiro problema: dizer o texto como se tivesse sido pensado e falado pela primeira vez, renovado a cada performance e ao mesmo tempo idêntico ao texto escrito: hic et nunc.

Agora chegamos ao cerne da questão: como fazer? Penso que se o ator considera o trabalho de memorização como um tipo de trabalho forçado, monótono, um mal necessário, mecânico, quase passivo, sofrerá suas consequências nefastas, tanto durante os ensaios como durante as apresentações. Entretanto, se considerar este trabalho como uma oportunidade de exercitar sua inteligência tanto do texto como de sua própria relação com o texto e também como uma conquista, uma apropriação do texto, o mais difícil será superado; a tarefa torna-se então interessante para não dizer apaixonante. Para isso, porém, é preciso muita paciência e tempo. Emprego um método muito preciso, mas flexível e adaptável a pratica-

Academy de New York em 22/02/1969 e publicado em 1980 na revista "Dialog” n5 . Em seguida, foi traduzido do polonês e publicado em italiano por Carla Pollastrelli (1980 Editora "La casa Usher"), depois foi revisado e publicado em "Jerzy Grotowski - Testi 1968 - 1998", aos cuidados de Antonio Attisani e Mario Biagini (2007 Bulzoni Editore). Encontrei este texto depois de escrever este ensaio, após uma conversa com Tatiana Motta Lima sobre a origem do uso do termo "organicidade" por Grotowski e sua relação com a tradição de Stanislavski.

2 No conjunto deste texto falo evidentemente do ator ocidental, e não do ator tradicional oriental, para quem a memorização é integrada à aprendizagem da profissão. Isto acontecia sem dúvida no ocidente no passado, mas de uma maneira muito diferente, muito ligada à tradição da retórica clássica. 
mente todas as situações. No entanto, relembro que é meramente um método, não mais que isso e que cada texto, cada situação teatral, cada grupo de teatro e cada ator requer um trabalho de memorização um pouco diferente.

Este trabalho de memorização se pratica em três fases: a fase escrita, ${ }^{3}$ a fase pensada e a fase composta.

\section{Fase escrita}

Aprendo o texto copiando-o (faço sempre com papel e caneta, mas imagino que também possa funcionar com um teclado de computador) até ser capaz de escrevê-lo de maneira precisa, num ritmo continuo, sem hesitação ou correção, tanto no que diz respeito à ortografia quanto à pontuação e mesmo à disposição das palavras quando, por exemplo, se trata de versos. Com este objetivo em mente, trabalho com fragmentos lógicos do texto, respeitando o sentido e a estrutura das frases que se encadeiam em parágrafos ou em réplicas, ${ }^{4}$ depois em cenas ou quadros ou qualquer outra unidade de sentido. O que é fundamental é o respeito à forma (pontuação, ortografia) em seus mínimos detalhes e ao sentido. Em outras palavras, enquanto escrevemos, neste primeiro momento, devemos compreender o sentido literal do que está sendo escrito.

O que acontece quando fazemos o trabalho de memorização através da escrita? Aprendemos o texto num ritmo mais lento do que o ritmo da linguagem falada. Com isso, temos tempo de refletir sobre o sentido do texto e além disso, acolher as associações subjetivas que brotarem (música, imagem, odores, sensaçōes, lembranças, emoçôes...) Assim, podemos receber as ressonâncias do texto em nós mesmos e entender o texto sem pronunciá-lo. ${ }^{5}$ Compreende-se facilmente que esta memorização, sem pronunciar ou articular o texto, tem a vantagem fundamental de fixar o texto, sem gravar sua interpretação, sua enunciação, sua musicalidade ou seu ritmo. Isto é essencial para o desenvolvimento do trabalho, ou seja, para os ensaios.

Podemos a qualquer momento, trabalhando sozinhos, corrigir os erros e as imprecisões, notar as hesitaçōes e os esquecimentos que cometemos, e isto pelo simples cotejo do texto que acabamos de escrever com o original. Corrigem-se assim imediatamente os erros, sem

3 Falo, é claro, da memorização de um texto na língua materna do ator. Em caso contrário, e sobretudo se a língua não é perfeitamente conhecida, todo o processo é diferente (e eu falo com conhecimento de causa pois trabalhei nas três situaçôes: em francês, que é minha língua materna, em italiano, que é minha segunda língua e que agora já não tenho mais bloqueios mentais; e enfim em inglês e português, em níveis diferentes, que ainda requerem um esforço de adaptação). É preciso neste último caso começar a resolver os problemas de sentido e de pronúncia antes de começarmos a memorização escrita do texto. Isto posto, sempre é bom lembrar que não há um método ou regra absoluta no trabalho teatral, somente práticas mais ou menos bem adaptadas a um determinado objetivo.

4 Quando se trata de diálogos, não se pode evitar aprender as réplicas dos outros atores.

5 Suponho que isto tenha a ver com as diferentes áreas do córtex cerebral que estão implicadas em todo trabalho de memorização. Memorizar escrevendo convoca uma área motriz, a dos dedos da mão, que é muito diferente daquela da fonação (movimento dos lábios, língua, garganta, etc..). Parece que quanto mais convocamos áreas diferentes do córtex cerebral, mais se desenvolvem qualidades distintas que enriquecem o trabalho. Isto me leva também a relembrar que neste trabalho de memorização, a postura física da pessoa que memoriza influi na qualidade do trabalho. As posturas de relaxamento do corpo são contraproducentes. Ao contrário, as posturas mais comprometidas, atentas e alertas facilitam consideravelmente a memorização, em todas as fases. 
fixá-los e sem a ajuda de outra pessoa; erros que, de outro modo, logo se acumulariam, se tornariam repetitivos e constituiriam verdadeiras armadilhas para nossa memória.

Enfim, à medida que a memorização progride, começamos a nos apossar fisicamente do texto, a torná-lo nosso. Tal apropriação cria um vínculo muito forte entre o ator e "seu" texto, constituindo o fundamento do respeito a todos os sentidos do texto.

\section{Fase mental}

Quando o trabalho de memorização pela escrita parece terminado, passamos para a fase da memorização mental. Utilizo esta palavra como na expressão "cálculo mental", o exercício que na escola obriga o aluno a fazer as operações matemáticas de cabeça, sem escrever no papel ou no quadro negro. Se pensarmos nisto, podemos imaginar o salto de qualidade entre a memorização escrita e a memorização mental. Há uma espécie de esforço a mais que nos obriga a ter em mente a parte e o todo, a série de operações e a operação geral.

No começo, devemos descobrir que tipo de processo mental é dominante para nós como atores. Associamos involuntariamente o encadeamento das palavras e das idéias aos objetos, para fixá-los com precisão e ordem. É deste processo inconsciente que emerge a dominante mental e sensorial (a visão, a audição, o tato) que determina nossa maneira de ser e de nos exprimir. Para alguns, trata-se de imagens, para outros, de música e ritmo, para outros ainda, de percepções táteis. Quando repassamos um texto mentalmente, nossos olhos nos traem, orien- tando-se para uma direção ou outra, conforme associamos o texto a imagens ou a sons, a fantasias ou lembranças vividas. Esta é a primeira etapa da memorização mental. É o momento também em que devemos lutar contra a tentação de dizer o texto em voz alta para "reencontrá-lo". 6

Em seguida, é preciso dominar estes automatismos e adquirir um tipo de liberdade que passa pela divisão da atenção. No inicio, toda nossa atenção é dirigida somente para a memória do texto. Passa-se o texto numa situação protegida de distrações (por exemplo, numa sala calma e silenciosa) até poder percorrer mentalmente o texto da maneira mais fluida possível, sem erro ou interrupção. A ênfase aqui é: precisão e velocidade. Depois, é preciso dividir a atenção, por exemplo, obrigando-se a fazer uma atividade corporal bem completa (correr, fazer exercícios físicos, nadar...) ou então uma atividade manual que requer precisão (costurar, lavar a louça, cortar lenha etc..) sempre passando mentalmente o texto na cabeça sem perder o rigor, a fluência e sem esquecer, é claro, da atenção.

Enfim, é preciso dividir ainda mais a atenção, colocando-se em situaçôes cada vez mais perturbadoras, dispersivas, por exemplo, trabalhar num lugar muito barulhento, com muita gente, como numa rua bem agitada ou então, durante um grande esforço físico contínuo, como subir uma ladeira de bicicleta. Cada um deve escolher o que é mais divertido, mas que seja também um verdadeiro desafio. É um treino, pois, se vocês experimentarem este tipo de exercício, verão que no começo, se consegue manter a atenção necessária no texto apenas por um período muito curto. Mas, pouco a pouco, o tempo da atenção e, portanto, a

6 Ressalto uma coisa que o ator, quando está memorizando, deve tentar evitar a todo custo: voltar atrás. Se bloquearmos uma palavra, uma passagem de uma frase à outra não devemos voltar atrás para pular o obstáculo. Isto não funciona e corre-se o risco de aumentar a tensão, quando a menor dificuldade com o texto aparecer durante os ensaios. 
quantidade de texto passado mentalmente aumenta, indo até um certo ponto, que é muito difícil de ultrapassar. ${ }^{7}$

O desafio deste método de memorização consiste em tentar não fraquejar e nunca pronunciar o texto antes de ter diante de si um interlocutor de peso, quero dizer, um ou mais atores da mesma cena. Esse trabalho também deve ser feito em presença do diretor. Por quê? Porque este tipo de memorização pode trazer verdadeiras surpresas, provocar a descoberta de uma interpretação, de uma associação, de uma emoção escondida que vem à tona na primeira vez que o texto é enunciado. É algo imprevisível, não preparado, que pode ser muito delicado e quase invisível, mas, às vezes, é fundamental para o resto do trabalho.

\section{Fase composta}

Rapidamente, durante os ensaios, o texto começa a se associar a situações, relações, ações com os outros atores, com o espaço, com o tempo. $\mathrm{O}$ ator cria um tipo de partitura (como uma partitura musical) incluindo todos estes fatores, os contatos com os outros, os ritmos, os movimentos e claro, todas as associaçōes subjetivas, as intençôes, as nuances. $\mathrm{O}$ texto se torna organicamente ligado a esta partitura e cria um tipo de frase, assim como um instrumento numa orquestra tem sua própria frase, mas leva em conta as frases dos outros instrumentos. Tudo isto se memoriza inconscientemente e nos menores detalhes para o ator: é a partitura do ator. Mas, algumas vezes pode ocorrer que durante o trabalho, $\mathrm{o}$ ator volte a encontrar dificuldades com alguma passagem do texto. É neste momento que ele descobre um dos verdadeiros interesses em se memorizar o texto dessa maneira. Primeiramente, ele pode voltar para a memória escrita e verificar sozinho, sem necessidade de uma supervisão externa, a precisão do texto. Por outro lado, ele pode repassar mentalmente a cena em sua cabeça, anexando a ela os impulsos que são as verdadeiras unidades estruturais de sua partitura. E para isso só precisará sentar-se num lugar tranquilo e trabalhar. ${ }^{8}$

É preciso notar que esta prática de memorização voluntária do texto não está ligada obrigatoriamente ao trabalho de improvisação estruturada, que será o tema do próximo capitulo. Ou seja, se neste último caso, ela é praticamente indispensável, também pode ser aplicada a situaçōes muito mais convencionais ou formais do trabalho teatral. Entretanto, ela não deve nunca ser pensada como uma metodologia absoluta, o que seria um equivoco, teatralmente falando. Tudo depende das pessoas envolvidas, da situação e também, é lógico, do tempo disponível para a memorização.

\section{Prática da memória involuntária: a improvisação estruturada.}

A improvisação é uma palavra que gera muita confusão: significa, a princípio, atuar no calor da hora e sem preparação. Agora, se pensamos no trabalho do ator durante os ensaios, a im-

No meu caso, numa situação muito dispersiva dificilmente passo dos 20 minutos de exercício contínuo. Como esta atividade requer um grande esforço físico e mental, é inútil se forçar; é muito melhor dividir o trabalho, deixando a cabeça descansar o suficiente, entre um exercício e outro. Não devemos esquecer também que a cabeça "trabalha" sozinha durante o sono.

8 Soube que no final de sua vida, o pianista Glenn Gould nem precisava de um piano ou de um teclado mudo para ensaiar sua interpretação. Sentava-se e passava, imóvel, o trecho da música na sua cabeça. Suponho que permaneciam somente os impulsos mas quase invisíveis, sob sua pele, sem mesmo mover os dedos. 
provisação toma um sentido um pouco diferente. Trata-se do ponto de partida de um processo criativo que, ao se desenvolver, vai constituir o material de base para a construção de um espetáculo, ou seja, uma improvisação estruturada. Essa expressão comporta certa ambiguidade e justamente por isso traduz muito bem o paradoxo fundamental do trabalho teatral: o ator deve atuar ${ }^{9}$ hic et nunc como se agisse na hora $\mathrm{e}$ sem preparação; e ao mesmo tempo tem que ser capaz de repetir esta mesma ação a cada performance; uma ação diferente em suas micro-variações, mas cuja estrutura permanece idêntica.

Assim, a improvisação estruturada é um trabalho quase oposto ao trabalho de memorização, já que leva o ator da liberdade de improvisação à estrutura. Porém, o rigor é o mesmo. Este trabalho de improvisação acontece durante os ensaios e exige a presença de um observador, o encenador, para adquirir sentido e objetividade. Vou me limitar à improvisação estruturada individual. É um trabalho muito complexo e passa por diversas fases: a) a pesquisa ativa de lembranças ou de associações expressivas para montar uma cena: a exploração; b) a elaboração de uma estrutura para fixar e repetir cada cena: a partitura; c) a manutenção viva da partitura: a proteção.

Ao enumerar as três etapas, parece que já não falo mais de memória. Mas, ao contrário: trata-se da memória, mas involuntária, que está vinculada à intuição e a errância, ao tatear e ao tentar. É a memória corporal, ligada às diferentes percepções sensoriais: visão, audição, olfato, gosto, tato e cinestesia (a sensação interna do movimento e das partes do corpo). É também a memória ligada às lembranças perdidas no sub- consciente, que só aparecem involuntariamente e muitas vezes em associação com uma percepção do corpo. ${ }^{10}$

\section{A exploração}

No inicio há um tema escolhido pelo ator ou o encenador. A procura de uma associação ou de uma lembrança esquecida começa sempre pela evocação de uma associação ou de uma recordação imediatamente disponível. É como entrar numa sala com portas que podem se abrir para o desconhecido ou o esquecido. Quando falo de evocação, trata-se realmente de um trabalho psicofísico do ator. Não estamos falando de sentar e analisar, mas de utilizar a primeira coisa que vem a mente, sem julgamento prévio. Pode parecer simplista ou mesmo uma bobagem, mas é preciso literalmente se jogar numa improvisação sobre o tema escolhido. Para tal, é preciso um tanto de coragem e uma confiança absoluta nas pessoas que assistem. Finalmente, não se trata de um trabalho de análise didática ou de pesquisa histórica; quero dizer que não importa saber se é um fato real escondido no subconsciente ou uma fantasia, ou ainda, um tipo de colagem de diferentes elementos heterogêneos. Isto não tem a mínima importância. $\mathrm{O}$ que se busca é a qualidade energética do que é evocado, sua riqueza de detalhes concretos, sua coerência e claro, a curiosidade que isto levanta naquele que o evoca.

$\mathrm{Na}$ improvisação, é preciso tentar ser muito concreto e até mesmo empregar elementos próximos da imitação e da pantomima. ${ }^{11}$ Não se deve buscar um estado emotivo particu-

9 Uso aqui a palavra "agir" e "ação" para significar tudo que um ator faz em cena, tanto dizer o texto quanto fazer ações propriamente ditas ou estar em relação com os outros.

10 É preciso ler "Em busca do tempo perdido" de Marcel Proust para compreender toda riqueza deste processo fundamental da memória.

11 Não raro, os atores que alegam ser da vanguarda teatral sentem-se incomodados de usar técnicas tão primárias como a imitação ou a pantomima. É um equivoco. Em primeiro lugar, é muito difícil fazer 
lar: fugidias, as emoções não se convocam pela vontade. $\mathrm{O}$ ator deve apenas registrar sua presença, evitando amplificá-las artificialmente ou tentar segurá-las ou agarrá-las. Enfim, não deve mergulhar numa exaltação ou pseudo-transe cujo efeito é tão somente inibir as memórias precisas da improvisação e, por consequencia, todo trabalho de estruturação. Trata-se na realidade da? consigo mesmo, sem qualquer autocomplacência. É preciso buscar o que parece ser mais concreto e pulsante. Um dos critérios para se orientar é a presença na improvisação de detalhes precisos e especificos, originais $\mathrm{E}$ surpreendentes, sem a presença de clichês.

É bem raro que a primeira improvisação se torne a base do trabalho de estruturação; Algumas vezes, a primeira improvisação não funciona, mas abre caminho para outras improvisações. Por exemplo, durante a primeira improvisação aparece uma associação ou uma lembrança extremamente vital e precisa, que não tem nada a ver, aparentemente, com a direção inicial, mas que se impõe com clareza. Então a tarefa passa a ser explorar esta nova fonte que vai se tornar o âmago da próxima improvisação. A primeiríssima improvisação toca qualquer coisa que se torna o catalisador da segunda improvisação. Por isso, não se deve eliminar imediatamente a primeira improvisação, mesmo se, a princípio, parece sem graça ou insignificante. Deve-se repeti-la uma vez mais, para encontrar a passagem precisa entre uma improvisação e a próxima. Somente durante a etapa seguinte, a estruturação, será possível descartar completamente a primeira improvisação ou talvez conservar algum fragmento pertinente.

Finalmente, quando temos a intuição de tocar em algo interessante, é preciso repetir várias vezes para explorar ao máximo os detalhes. Mas é preciso agir com delicadeza, sem sentimentalismos (não jogar com as emoções) e sem forçar o corpo, a voz. Não se trata de demonstrar a quem assiste o que se passa, mas de deixar transparecer, de seguir o fio da recordação ou da intuição. ${ }^{12}$

\section{A estruturação}

Depois de ter encontrado o verdadeiro tema da improvisação e de explorá-lo, começa então a fase de estruturação. É uma fase fundamental, necessária, mas árida. É preciso compreender os diferentes elementos que constituem a improvisação e como se articulam entre si. Como condensar a improvisação (muitas vezes a im-

isso direito e depois pode ser útil porque despretensioso, convoca de verdade o corpo muito mais do que o mental, e estimula a memória e a fantasia. Por exemplo, se devemos evocar uma pessoa, é preciso tentar encontrar sua maneira de andar, de se sentar, de olhar, encontrar seus gestos e suas entonaçóes de voz. Se for preciso evocar um acontecimento, é preciso tentar encontrar a sequência de açóes, os lugares precisos no espaço, a luz e a temperatura etc... Não é tanto o número de detalhes evocados que conta, mas a sua qualidade de evocação como Marcel Proust o explica perfeitamente: um detalhe específico é suficiente para fazer ressurgir o conjunto, para dar vida à recordação. Neste sentido o processo de exploração entra em comunicação com o processo escondido da memória involuntária.

12 Muitas vezes é útil tomar notas das improvisações para não perder os detalhes. Tais anotações devem permanecer absolutamente pessoais. Porque não contar, por exemplo, ao diretor ou ao colega de trabalho sua própria improvisação? Porque muito facilmente o que é vivido pela lembrança ou pela fantasia perde seu brilho, se ofusca e morre quando tentamos verbalizar de uma forma lógica. Quando tomamos notas, tentamos anotar só o estritamente necessário, para lembrar a sequência de detalhes que constituem a improvisação. Quando contamos algo, ao contrário, acrescentamos lógica, sentimento, justificativas, explicações e tudo se torna árido. 
provisação é longa, cheia de repetições, de hesitaçōes) sem perder o menor detalhe. É um trabalho bem minucioso que lembra um pouco uma montagem cinematográfica e que, em geral, dá a impressão de tirar todo frescor da ação. Por ser frio e técnico, pode ser uma verdadeira dificuldade para o ator. Requer também muito tato por parte do diretor, pois ele não deve dar a impressão de manipular o ator e sim de ajudálo a organizar o que foi criado, encontrando a forma adequada.

É durante esta fase que se apresenta o problema do texto (já memorizado) que é parte integrante da estrutura. A questão verdadeira é: qual é o fluxo dominante, o texto ou a ação? Em função da resposta, o ator integrará o texto nos espaços livres de ação ou, inversamente, o ator integrará a ação entre os fragmentos do texto. Inicialmente, como ator e como diretor, eu preferia separar o texto da ação para, pouco a pouco, compreender onde o texto e ação se superpóem e onde se revezam. Claro que isso é, no começo, muito formal mas, pela repetição e rigor, torna-se flexível e fluente. Para o ator, os detalhes vão, gradativamente, achando seu lugar no tempo e no espaço. A atenção, que no começo é caótica e fragmentada, começa a se organizar em um fluxo contínuo. Em vez de saltar de um assunto a outro, ela passa a caminhar em diversas direções ao mesmo tempo. Em particular, o ator começa a seguir o que acontece no exterior sem cortar o fio interior de sua evocação. Uma verdadeira partitura de impulsos se cria e se inscreve no corpo, na voz e na mente do ator. $\mathrm{O}$ ator tem os olhos bem abertos ao que se passa à sua volta e ao mesmo tempo está ancorado em sua realidade interna.

\section{A proteção}

$\mathrm{O}$ ator e o diretor são responsáveis pela verdadeira proteção da improvisação. É preciso seguir certas regras fundamentais. Quando o ator improvisa seriamente, revela aspectos muito íntimos de sua vida particular e de sua personali- dade, colocando-se numa posição de grande fragilidade. Não se deve comentar nem descrever as improvisações, nem fazer brincadeiras sobre elas (ver nota 13) pois corre-se o risco não somente de destruir a improvisação mas, o que é mais grave, de destruir também a confiança necessária entre as pessoas que trabalham juntas.

Isto não quer dizer que o ator e o diretor não podem falar sobre as improvisações. No entanto devem discutir de maneira bem pragmática, limitando-se ao nível descritivo das ações sem entrar em análises psicológicas ou emocionais da improvisação. É preciso compreender bem que o que é apreendido do exterior (o ponto de vista do diretor) pode ser totalmente diferente da percepção de quem atua. Seu processo mental, suas razões, suas associações, suas recordações tornam-se invisíveis ao outro e é bom que seja assim.

É preciso proteger a improvisação estruturada contra tendências perigosas. Antes de tudo, é preciso evitar as simplificações pela gradativa eliminação de detalhes muito pequenos, aparentemente insignificantes, mas que constituem a verdadeira seiva do trabalho, exatamente aquilo que faz a improvisação permanecer vital, única, enraizada na memória corporal daquele que a criou e, deste modo, impossível de ser reproduzida por outro ator. Sem o detalhe, perdemos a vitalidade e reaparecem os clichês, os lugares comuns, as açôes simbólicas.

Em segundo lugar, é preciso evitar a todo custo o bombeamento, ou seja, qualquer tipo de exagero na voz, nos gestos e na respiração para aumentar as emoçôes do ator, acreditando erroneamente que isto provocará o mesmo no espectador. Este tipo de atitude é extremamente nocivo porque conduz a atenção do ator para a emoção que ele sente ou que gostaria de sentir (e todos nós sabemos aonde leva esta mentira) e assim ele se desliga pouco a pouco da conexão com os outros, com o exterior. O barulho, a gesticulação, o excesso impedem-no de perceber o que se passa tanto fora como dentro dele. Rompe-se o fio interior do ator e o que resta é um simulacro de improvisação, narcísica e 
ineficiente. De um minuto a outro, o filme se queimou: a improvisação está esvaziada de sentido e de credibilidade.

Por fim, há o perigo de se banalizar a improvisação pelo número excessivo de ensaios técnicos. O que é um ensaio técnico? É trabalhar a estrutura da improvisação, sem um compromisso pleno do ator na ação. Estes ensaios são necessários, mas é preciso não manipular demais a matéria viva. Quando uma improvisação toca em pontos evidentemente sensíveis, carregados emocionalmente, é preciso tentar recriar cada vez que se toca neste ponto, uma situação não cotidiana, nem técnica nem espetacular, uma situação protegida que permita ao ator ficar totalmente concentrado na sua linha de trabalho, sem qualquer preocupação com o espetáculo, mas diante do olhar sincero do encenador.

Em geral, devemos evitar raciocínios muito mecânicos e funcionais com a improvisação estruturada: não se trata de uma máquina, nem de um motor, nem de um computador. Não é suficiente montar uma cena correta, numa ordem correta, com a energia correta. A improvisação tem algo de vital, de sutil e de misterioso. Não se deve e não se pode explicar tudo. Por exemplo, quando proponho que o processo de improvisação se organize em três etapas - exploração, estruturação e proteção - isto é ilusório, é uma espécie de simplificação utilizada para me fazer entender. Na realidade tudo é muito mais complexo e dinâmico. Claro que é preciso começar pela exploração, o que não quer dizer que a exploração cesse quando começa a estruturação. Quanto à estruturação, esta já está presente durante as primeiras improvisações, pois as escolhas já estão ocorrendo. A proteção também se entrelaça ao trabalho de exploração. Finalmente, não há regras fixas dizendo que tal detalhe ou tal lembrança justa e fértil não possa se apresentar no começo, no meio ou no fim do trabalho e ser decisiva para a totalidade da linha da recordação ou da composição do personagem; ou que tal associação que apareceu no final da estruturação, não possa trazer uma mudança radical no tom geral do trabalho.

Quando observo um ator trabalhar uma improvisação, certas características objetivas da ação estimulam a minha atenção e me levam a pensar "isso funciona" ou "isso não funciona" ou, em outras palavras, "acredito" ou "não acredito". O ator não faz barulhos inúteis nem com os pés nem com a respiração. Não força a voz nem o corpo. Não se isola e percebe tudo a sua volta. Não tenta explicar o que faz e não usa clichês. Está inteiramente envolvido com seu corpo, e principalmente com sua coluna vertebral, naquilo que faz. Segue o fio condutor interno de sua partitura que apresenta detalhes ricos, mutantes e surpreendentes. Olha de verdade para os outros, fala de verdade com eles e escuta de verdade o que eles dizem.

Quando eu mesmo trabalho em uma improvisação, quais são os sinais que me indicam que estou no caminho certo? Primeiramente, há o efeito surpresa de uma recordação ou uma associação, totalmente imprevistas mas evidentes. Em seguida, há um tipo de clareza ou de vivacidade de sensações ou de associações (um pouco como o hiperrealismo na pintura ou o caráter numinoso descrito por C.G. Jung). Finalmente, há a impressão de seguir um fio frágil mas real, inscrito no corpo e no coração, que orienta todo o trabalho. Mas tudo isto só acontece se, no momento em que se produz, eu não fixo minha atenção sobre os signos e sim sobre o trabalho; pois de outra maneira tudo se esvanece como fumaça.

\section{Reflexões sobre a organicidade da memória}

Se insisto nestes dois elementos aparentemente muito técnicos do meu trabalho, a memorização e a improvisação estruturada, é porque tocam um ponto essencial para o ator: a organicidade do seu trabalho. A organicidade é um conceito propriamente grotowskiano que se re- 
fere ao trabalho do ator, mas não somente. ${ }^{13}$ Há inúmeras interpretaçôes deste termo, mas minha intenção aqui, não é discuti-lo; e sim utilizá-lo como compreendi quando trabalhei com Jerzy Grotowski. Para mim, a organicidade é uma qualidade muito particular da presença e da ação no trabalho do ator. Tem uma relação muito direta com a não-separação do corpo e da mente, ${ }^{14}$ um tipo de passividade ativa que permite quebrar a barreira entre ação e pensamento, percepção e consciência, decisão e ação. Para utilizar uma imagem simples, a organicidade parece uma perfeita adequação de um animal com o mundo à sua volta. É bem verdade que não somos mais que animais humanos, e toda nossa educação nos leva ao controle de nossos comportamentos, de nossas emoções e até mesmo de nossas percepções (não é um julgamento de valor, é uma simples constatação). Para resgatar nossa organicidade original, no sentido do recém-nascido, é preciso reanimar a memória de nossa animalidade em nosso corpo. É aí que se manifesta a organicidade, na qualidade de nossa atenção, na origem e na energia de nossos movimentos, na fluência de nossa voz, no silêncio de nossa presença, na precisão de nosso olhar e de nossa postura.
Examinemos agora a relação entre memória e organicidade. Para atingir a organicidade na improvisação, o ator deve se conectar com a memória corporal e o subconsciente ou, em outras palavras, ativar sua intuição e abandonar uma parte do controle lógico, racional que barra o processo. Insisto que é uma parte do controle e não todo o controle: é necessário sempre ter bom senso, manter a auto-proteção física, e digamos, a memorização automática do que acontece. Não há nenhum interesse em se colocar num tipo de estado de exaltação mental que teria como consequência o esquecimento do que é mais importante, os detalhes, e que assim, nos levaria à inconsistência do conjunto. Em seguida, é preciso realizar a estruturação da improvisação, que é como uma operação alquímica de transformação. Os restos, os elementos inúteis, serão eliminados assim como as redundâncias e os tempos mortos. Será preciso esculpir cada detalhe, porém compreender também a economia da energia e, enfim, introduzir certos elementos estranhos à improvisação. E aí nos encontramos diante de alguma coisa aparentemente contraditória: o material introduzido ${ }^{15}$ pertence à memória voluntária ao passo que o material vindo da improvisação pertence à me-

13 O conceito de organicidade se refere ao ator mas também à pessoa que participa de um ritual, cantor, dançarino ou guia (como o "Stalker" no filme de Tarkovsky) de uma ação para-teatral: todos os que podem ser considerados "performers". Minha experiência prática com Jerzy Grotowski se situa entre os anos 1973 e 1985, quer dizer, entre o período do chamado "trabalho para-teatral" e o período da "arte como veiculo", isto é centrados em dois projetos principais "Holiday" e "Teatro das Fontes". Eu era um guia para as atividades para-teatrais e portanto não fiz trabalho como ator com Jerzy Grotowski, mesmo se durante o último estágio do qual participei em 1985, meu trabalho estava muito próximo do trabalho do ator, tanto que isto motivou minha volta ao teatro e à cena.

14 "O mental" é um termo empregado por Grotowski para designar a atividade mental em seu conjunto, sem qualquer conotação intelectual ou espiritual. É um termo pragmático cujo equivalente em inglês é "the mind".

15 Certamente trata-se em primeiro lugar do texto, mas também de numerosas modificações técnicas que vão da simples orientação no espaço aos deslocamentos necessários, à introdução de objetos, à utilização de figurinos, ao volume da voz, ao ritmo da ação, enfim tudo que vai transformar esta improvisação em partitura e depois em fragmento de um espetáculo. 
mória involuntária. Será preciso então forjar um novo material mesclando as duas memórias. Por experiência própria, posso dizer que é preciso agir muito gradativamente, especialmente com o texto. Para mim, no começo, é melhor separar texto e ação: na prática, interromper o texto para fazer a ação e interromper a ação para falar o texto. Tudo é feito por tentativa e erro, mas também guiado pelo bom senso que nos indica onde o texto pode ser suspenso, sem perder seu sentido e sua energia e onde a ação pode ser suspensa, sem perder seu sentido e sua energia. Em certos casos, a ação se torna um tipo de correnteza sobre a qual o texto vem flutuar como um barco. Em outros casos, é a ação que vem como que habitar dentro do texto e o leva. Re- pito: não há nenhuma regra geral, nenhum método. Tudo que sei é que se trata de uma matéria vital e frágil e que é preciso trabalhá-la com atenção e sem forçar. Assim, a memória voluntária continua a manter o rigor do texto, as restrições técnicas e inter-humanas, enquanto que a memória involuntária continua a alimentar a fonte primeira da criação, registrando com fidelidade o que surge durante o trabalho. Somente assim podemos preservar a organicidade do trabalho, esta ausência de corte entre o mental e o corporal, esta conjunção entre opostos: precisão e espontaneidade. Somente assim $o$ ator pode reencontrar a cada performance $o$ fio condutor que o conecta à fonte vital de seu ato criativo.

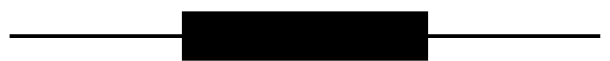

RESUMO: Na primeira parte do artigo, o autor propõe um método prático para auxiliar o ator no processo de memorização de um texto, utilizando a memória voluntária. Já na segunda parte, o autor delineia o método que denominou de "improvisação estruturada" bb no qual se emprega a memória involuntária.

PALAVRAS-CHAVE: método, memória, ator, memorização, improvisação. 